\title{
Serum Concentration of the Pyridinoline Cross-Linked Carboxyterminal Telopeptide of Type I Collagen (ICTP) Is a Useful Indicator of Decline and Recovery of Bone Mineral Density in Lumbar Spine: Analysis in Japanese Postmenopausal Women With or Without Hormone Replacement
}

\author{
TAKEHIKo YASUMIZU, KAZUHIKo HOSHI, Sumio IIJIMA* AND AKIo ASAKA* \\ Department of Obstetrics and Gynecology and *Department of Health Science, \\ Yamanashi Medical University, Yamanashi 409-3898, Japan
}

\begin{abstract}
To reassess the clinical utility of serum pyridinoline cross-linked carboxyterminal telopeptide of type I collagen (ICTP), a promising but controversial indicator of bone resorption, we evaluated its performance as a biochemical marker in a 6-month study of a strictly selected population of 76 Japanese postmenopausal and healthy women, 33 recipients of hormone replacement therapy and 43 nonrecipients. We measured bone mineral density (BMD) of the lumbar spine $\left(\mathrm{L}_{2}-\mathrm{L}_{4}\right)$, and serum ICTP, carboxyterminal propeptide of type I procollagen (PICP) and other conventional serum biochemical markers, e.g. bone gla protein (BGP), alkaline phosphatase, calcium and phosphate at the entry and 6 months later. We calculated the percent change between the baseline and 6 -month values $(\Delta \%)$ in lumbar BMD and the biochemical markers, individually, and compared the degree of correlations between $\Delta \%$ in BMD and that in the biochemical markers. $\Delta \%$ in ICTP and $\Delta \%$ in BGP correlated with $\Delta \%$ in BMD negatively and significantly. Especially $\Delta \%$ in ICTP correlated with that in BMD to a high degree $(P<0.0001)$. No significant correlation was observed in other biochemical markers. We concluded that serum ICTP is a sensitive and useful bone resorption marker in the postmenopausal population, which strongly correlates with the change in BMD.
\end{abstract}

Key words: Bone mineral density, Lumbar spine, Carboxyterminal telopeptide of type I collagen (ICTP), Carboxyterminal telopeptide of type I procollagen (PICP), Postmenopausal woman

(Endocrine Journal 45: 45-51, 1998)

BONE mineral measurement by dual-energy $X$-ray absorptiometry (DXA) now constitutes the most important noninvasive tool for diagnosis and follow-up of osteoporosis, because bone mineral content can be estimated with acceptable accuracy

Received: May 20, 1997

Accepted: September 30, 1997

Correspondence to: Dr. Takehiko YASUMIZU, Department of Obstetrics and Gynecology, Yamanashi Medical University, 1110 Shimokato, Tamaho, Nakakomagun, Yamanashi 409-3898, Japan and precision by means of this technique [1, 2]. Nevertheless, the bone mineral content at the actual time of the examination does not reflect the present status of bone metabolism, but rather the outcome of past bone turnover. A biochemical marker, or a panel of biochemical markers, of bone metabolism that could be measured in blood or urine has the potential to clarify the status of bone at any given time and would thus be useful as a back-up or alternative means not only in identifying women with high bone turnover, but also in following the response to treatment. Recently several promising 
bone-specific proteins as potential indicators for bone turnover have been purified and reliable assay systems for these proteins have been developed. Among these biochemical markers, two serum proteins produced during the synthesis and degradation of type I collagen, the carboxyterminal propeptide of type I procollagen (PICP) [3] and the pyridinoline cross-linked carboxyterminal telopeptide of type I collagen (ICTP) [4], are considered worthy of note, because type I collagen is the major constituent of bone and accounts for about $90 \%$ of the organic bone matrix [5]. These two proteins are considered to be specific to bone, and their performance as bone biochemical markers was found to be promising in the studies with a method of bone histomorphometry [6] or calcium kinetics [7]. Simultaneous determination of bone formation and resorption can therefore be made by measuring PICP and ICTP in serum specimens from the patients, if these assays are sensitive enough to detect pathological bone processes in the population of postmenopausal women. Most recent reports agree that serum PICP is a useful indicator of bone formation [8-11], but several authors concluded or pointed out that ICTP may not reflect such a minimum change as occurred in postmenopause, even though it may be a good marker of osteoporosis or metabolic bone disease [8-12].

In this prospective study, we aimed to reassess serum ICTP as a marker of bone metabolism and to evaluate the clinical utility of simultaneous determination of PICP and ICTP in a Japanese population of healthy postmenopausal women with or without hormone replacement treatment (HRT). We measured serum ICTP and PICP as well as other conventional serum biochemical markers in the subjects, and compared the degree of correlations between changes in bone mineral content of the lumbar spine and those in these biochemical markers.

\section{Subjects and Methods}

\section{Subjects}

The study population comprised 78 healthy postmenopausal women, aged 51-74 yr, who were all native Japanese and experienced natural menopause at least $3 \mathrm{yr}$ before the study. The criteria for exclusion of subjects from this study were 1) having a history of fractures of the distal forearm and hip, 2) using any drug known to affect bone metabolism or having any evident medical or surgical condition known to be associated with bone loss, 3) having vertebral fractures or severe deformities on lumbar and thoracic spinal radiographs, 4) having a high serum $17 \beta$-estradiol $\left(E_{2}\right)$ level $(\geq 20 \mathrm{pg} / \mathrm{ml})$ and 5$)$ having any abnormal serum values of albumin $(<33 \mathrm{~g} / \mathrm{L})$, alanine aminotransferase (ALT, > $40 \mathrm{U} / \mathrm{L}$ ), aspartate aminotransferase (AST, > $40 \mathrm{U} / \mathrm{L}$ ), or creatinine (> $80 \mu \mathrm{mol} / \mathrm{L}$ ). Spinal radiography and serum assays were performed 2-3 weeks before entry.

HRT was carried out according to an open design. All subjects were informed of the details of HRT, and $35(44.8 \%)$ of them volunteered to receive HRT (HRT group). In accordance with the Helsinki II Declaration, all participants gave their fully informed consent. For all participants, fasting venous blood was collected at $0900-1000 \mathrm{~h}$ and bone mineral density was measured in the afternoon on the day of beginning the study (baseline value) and 6 months later (6-month value). Serum was obtained immediately by centrifugation and stored at $-40{ }^{\circ} \mathrm{C}$ until analyzed. The women in the HRT group started to receive a 30 day-cycle of combination of $0.625 \mathrm{mg}$ of conjugated estrogen (Premarin, Asahi Kasei Co., Ltd., Tokyo: days 124) and $5 \mathrm{mg}$ of medroxyprogesterone acetate (Hysron, Kyowa Hakko Co., Ltd., Tokyo: days 1524) on the day after the baseline measurement. For 44 women without HRT (non-HRT group), a restriction was placed on the use of drugs known to affect bone metabolism during the study period.

Subsequently two patients in the HRT group withdrew from the study because of minor side effects (breast tenderness in one patient and fluid retention in one) and no 6-month examinations were performed. These withdrawals left 33 patients in the HRT group and 43 women in the non-HRT group. None of the 76 subjects suffered any diseases and/or injuries for which more than 3 days of hospitalization were required at any time during the study period, or had abnormal values of serum albumin, ALT, AST or creatinine in the 6-month samples.

\section{Bone mineral measurement}

Bone mineral content of the lumbar spine $\left(\mathrm{L}_{2}-\mathrm{L}_{4}\right)$ 
was measured antero-posteriorly by DXA (Hologic QDR 2000, Hologic, Inc., Waltham, MA, USA). Bone mineral content was expressed in terms of bone mineral density (BMD: $\mathrm{g} / \mathrm{cm}^{2}$ ). The coefficient of variation in the use of the equipment was found to be $0.34 \%$ for a spine phantom and $0.78 \%$ for healthy volunteers by our radiologists.

\section{Measurements of serum samples}

PICP and ICTP were measured with a radioimmunoassay (RIA) kit [3, 4] obtained from Orion Diagnostica (Oulunsalo, Finland). The concentration of intact bone gla protein (BGP) was determined with a two-site immunoradiometric assay (IRMA) kit [13] obtained from Mitsubishi Yuka (Tokyo). The intra- and inter-assay coefficients of variation were $3.2 \%$ and $5.6 \%$ for PICP, $3.9 \%$ and $6.1 \%$ for ICTP, and $2.9 \%$ and $7.3 \%$ for BGP, respectively. Serum calcium, phosphate, ALP, albumin, ALT, AST and creatinine levels were measured in our clinical laboratory by standard methods. $E_{2}$ was measured with an RIA kit [14] obtained from Daiichi Isotope, Co., Ltd. (Tokyo).

\section{Statistics}

All statistical analysis of the data was performed with SAS program software (SAS Institute; Cary, NC, USA). The balance of the distribution of subject characteristics between the two groups and the comparison of the outcome of parameters at the baseline with those at 6 months in each group were examined by the unpaired Wilcoxon rank sum test and paired Student's $t$ test, respectively. The correlations between the percent change from the baseline values $(\Delta \%)$ in BMD and that in each biochemical marker were determined by the simple regression analyses. The degree of correlation was expressed by Spearman's coefficient of correlation $\left(r_{s}\right)$. The statistical significance of the correlations was determined with the F test. For statistical comparison of means, data were expressed as the mean \pm SD unless otherwise indicated. Statistical significance was defined as $P<0.05$.

\section{Results}

Table 1 shows the demographic data on age, time elapsed since the onset of menopause, height, body weight and body mass index for the control and HRT groups. There were no significant differences between the two groups.

Table 2 shows the baseline and 6-month values for BMD and serum biochemical markers in the two groups. At the baseline, no significant differences between the two groups were detected for any parameter. At 6 months, significant changes were observed in all parameters except for phosphate in the HRT group; BMD increased and serum markers decreased, but no significant changes were observed in the non-HRT group.

The correlations between the percent change in

Table 1. Baseline characteristics of HRT and non-HRT groups

\begin{tabular}{lccc}
\hline & HRT $(\mathrm{n}=33)$ & Non-HRT (n=43) & \\
\hline Age (yr) & $59.4 \pm 7.1$ & $61.0 \pm 6.9$ & NS \\
Time since last & $10.8 \pm 6.7$ & $10.4 \pm 6.9$ & NS \\
$\quad$ bleeding (yr) & & & \\
Height (cm) & $152.1 \pm 5.7$ & $150.3 \pm 6.0$ & NS \\
Weight (kg) & $50.8 \pm 6.7$ & $52.3 \pm 8.2$ & NS \\
Body mass index & $23.3 \pm 3.3$ & $22.0 \pm 2.6$ & NS \\
\hline
\end{tabular}

NS, not significant.

Table 2. Parameter values at baseline and 6 months in HRT and non-HRT groups

\begin{tabular}{lccccccc}
\hline & \multicolumn{3}{c}{ HRT $(\mathrm{n}=33)$} & & \multicolumn{3}{c}{ Non-HRT $(\mathrm{N}=43)$} \\
\cline { 2 - 3 } & Baseline & 6 months & & & Baseline & 6 months \\
\hline Lumbar BMD $\left(\mathrm{g} / \mathrm{cm}^{2}\right)$ & $0.801 \pm 0.127$ & $0.831 \pm 0.126$ & $P<0.0001$ & & $0.827 \pm 0.150$ & $0.824 \pm 0.148$ & NS \\
PICP $(\mu \mathrm{g} / \mathrm{L})$ & $100.0 \pm 36.0$ & $94.6 \pm 39.3$ & $P=0.002$ & & $130.1 \pm 27.5$ & $105.8 \pm 32.1$ & NS \\
ICTP $(\mu \mathrm{g} / \mathrm{L})$ & $4.5 \pm 1.3$ & $3.0 \pm 0.8$ & $P<0.0001$ & & $4.3 \pm 1.2$ & $4.2 \pm 1.3$ & NS \\
BGP $(\mu \mathrm{g} / \mathrm{L})$ & $8.3 \pm 3.7$ & $6.8 \pm 3.2$ & $P=0.004$ & & $8.5 \pm 3.3$ & $9.0 \pm 3.7$ & NS \\
Ca $(\mathrm{mmol} / \mathrm{L})$ & $2.39 \pm 0.15$ & $2.31 \pm 0.11$ & $P=0.002$ & & $2.36 \pm 0.10$ & $2.32 \pm 0.12$ & NS \\
Phosphate $(\mathrm{mmol} / \mathrm{L})$ & $1.13 \pm 0.13$ & $1.01 \pm 0.14$ & NS & & $1.13 \pm 0.13$ & $1.10 \pm 0.15$ & NS \\
ALP (IU/L) & $179 \pm 51$ & $164 \pm 50$ & $P=0.003$ & & $182 \pm 56$ & $191 \pm 56$ & NS \\
\hline
\end{tabular}

NS, not significant. 
BMD and that in each biochemical marker in all subjects are shown in Fig. $1 . \Delta \%$ in ICTP and $\Delta \%$ in BGP correlated with $\Delta \%$ BMD negatively and significantly. The correlations between $\Delta \%$ in ICTP and $\Delta \%$ in BMD was especially high. No significant correlation was observed in other biochemical markers.

\section{Discussion}

In this study, we showed that serum ICTP reflects a change in lumbar BMD. The change in ICTP correlated with the change in BMD better than that in BGP. This means very good performance of ICTP as a marker of bone turnover, because serum BGP had been reported to be a good or even the best single predictor of the rate of bone loss in a cohort of peri- and postmenopausal women [15, 16]. Of the biochemical markers examined, ICTP correlated most significantly with the BMD change.

PICP decreased during HRT as same as other markers of bone formation, such as BGP and ALP, although the changes in these markers did not reflect the BMD change as sensitively as ICTP. The decrease in not only bone resorption markers but bone formation markers during HRT agreed with recent reports $[8,9]$, and supports the general concept that the effect of HRT on postmenopausal bone loss is caused by a reduction in bone resorption and a secondary decrease in bone formation, reflecting a decrease in the activation frequency of the new bone remodeling unit [17]. Differences in sensitivity observed between PICP, ICTP and BGP can be interpreted as being due to the differences in character as a biochemical marker. PICP and ICTP are essential bone formation and bone resorption markers, respectively, whereas BGP may reflect both bone formation and resorption, rather than bone formation alone $[8,18]$.

Although our study agreed with some previous studies which found that ICTP is a useful marker of bone resorption [6, 7], several other authors concluded or pointed out that ICTP is not a sensitive marker for estimating bone resorption [812]. Apparently there were considerable differences between these studies and ours in the subjects and the methods. All our subjects were healthy postmenopausal women with almost normal hepatic and renal functions, but the subjects in other studies were totally or partly osteoporotic women $[8,10,11]$ or much older women than ours [9]. Patients with a hepatic or renal disorder were ruled out as subjects in only two studies [9, 12], although serum levels of ICTP, PICP and BGP were reported to be influenced by hepatic or renal function $[4,19$, 20]. The study period was also different. A correlation between changes in BMD and those in biochemical markers was observed in only one study [10].

The most marked difference between our study and most of the others is the level of serum ICTP. The mean baseline ICTP value in our study population $(4.4 \mu \mathrm{g} / \mathrm{L})$ was considerably higher than those in other studies $(2-3 \mu \mathrm{g} / \mathrm{L})$ in spite of the fact that the sample collection and the assay method were almost the same. As a clue to explaining this discrepancy, Kushida et al. [10] obtained interesting results in the study of Japanese postmenopausal women, a similar population to ours. Although they did not find a significant difference between premenopausal and postmenopausal subjects in serum ICTP, ICTP levels in their osteoporotic subjects were higher than those in the studies of either an American $[8,9]$ or a European population $[11,12]$. Moreover, ICTP levels of their premenopausal group were almost the same as the 6-month levels in our HRT group. The difference between their study and ours in the mean ICTP level in postmenopausal women may originate in the criteria for subject selection. Their premenopausal subjects were younger than ours, because they defined the women with amenorrhea for at least $1 \mathrm{yr}$ since the last menstrual bleeding as menopausal. Since some ostensibly postmenopausal women maintain their ovarian activity [21], low ICTP levels of these women might have decreased the mean value in their premenopausal group. Since we selected the postmenopausal subjects more strictly according to the means of serum $\mathrm{E}_{2}$ determination, we could observe the effect of HRT clearly. Accordingly, bone turnover in Japanese postmenopausal women is proposed as being higher than that in European or American populations. This concept is supported by the evidence that the BMD of the spine and proximal femur measured by the same DXA machine was lower in Japanese women [22] than in American white women [23]. Considering that the detection limit of the ICTP assay was 0.34 

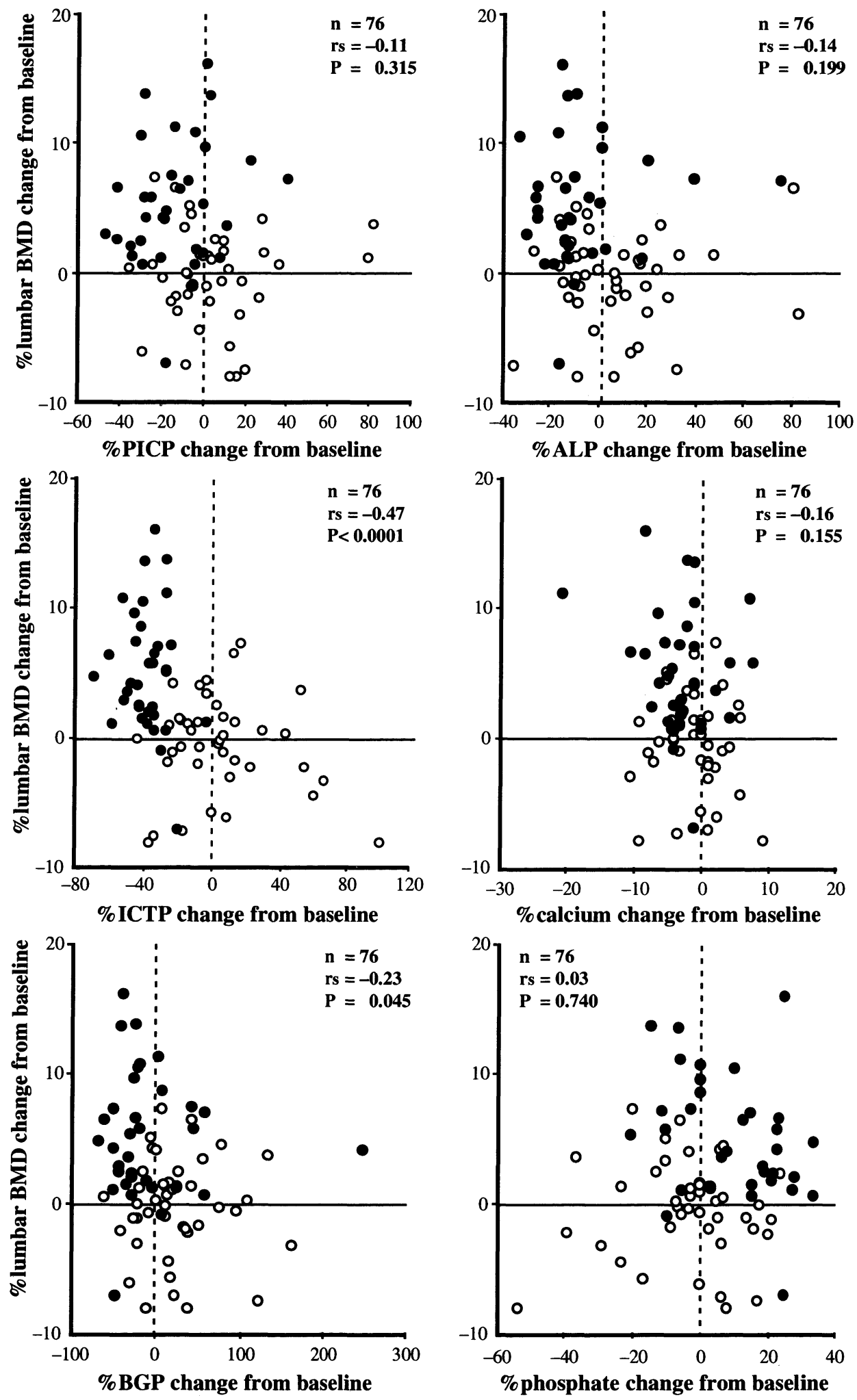

Fig. 1. Correlations between the percent change in BMD and that in each biochemical marker in all subjects. Filled and open circles indicate women in the HRT group and non-HRT group, respectively. 
$\mu \mathrm{g} / \mathrm{L}[4]$, the performance of ICTP as a biochemical marker seems to be reduced by a low serum level near the detection limit in European and American populations.

Recently urinary excretion of two cross-links, pyridinoline and deoxypyridinoline, was proposed as a potential marker of bone resorption [24]. More recently, type I collagen C-telepeptide in urine was reported to reflect bone resorption with more specificity [25]. Since we did not use these markers in this study, the comparison between serum ICTP and these urinary biochemical markers could not be discussed here.

In conclusion, the concentration of ICTP is a very sensitive bone resorption marker which strongly correlates with the change in BMD. ICTP therefore has the potential to be an ideal biochemical marker of bone resorption worldwide, if the sensitivity of the assay improves.

\section{Acknowledgments}

We are grateful to Diagnostica Division, Chugai Pharmaceutical Co., Ltd. (Tokyo) and Hachiouji Laboratory, SRL Co., Ltd. (Tokyo) for their cooperation in the measurement of PICP, ICTP and BGP. The present study was supported in part by Grants-in-Aid 06671635 and 08671878 provided by the Ministry of Education, Science and Culture of Japan.

\section{References}

1. Rizzouli R, Slosman D, Bonjour JP (1995) The role of dual energy X-ray absorptiometry of lumbar spine and proximal femur in the diagnosis and follow-up of osteoporosis. Am J Med 98 (suppl 2A): 33-36.

2. Koizumi K, Uchiyama G, Araki T, Hihara T, Ogata H, Monzawa S (1990) Fundamental evaluation of bone densitometry using dual energy $X$-ray absorptiometry (DEXA). Nippon Acta Radiologica 50: 123-129 (In Japanese).

3. Meikko J, Niemi S, Risteli J (1990) Radioimmunoassay of the carboxy-terminal propeptide of human type I procollagen. Clin Chem 36: 13281332.

4. Risteli J, Elomaa I, Niemi S, Novamo A, Risteli L (1993) Radioimmunoassay for the pyridinoline cross-linked carboxyl terminal telopeptide of type I collagen: A new serum marker of bone collagen degradation. Clin Chem 39: 635-640.

5. Deftos LJ (1991) Bone protein and peptide assays in the diagnosis and management of skeletal disease. Clin Chem 37: 1143-1148.

6. Eriksen EF, Charles P, Melsen F, Mosekilde L, Risteli L, Risteli J (1993) Serum markers of type I collagen formation and degradation in metabolic bone disease: Correlation with bone histomorphometry. J Bone Miner Res 8: 127-132.

7. Charles P, Mosekilde L, Risteli L, Risteli J, Eriksen EF (1994) Assessment of bone remodeling using biochemical indicators of type I collagen synthesis and degradation: Relation to calcium kinetics. Bone Miner 24: 81-94.

8. Prestwood KM, Pilbeam CC, Burleson JA, Woodiel FN, Delmas PD, Deftos LJ, Raisz LG (1994) The short term effects of conjugated estrogen on bone turnover in older women. J Clin Endocrinol Metab 79: 366-371.

9. Garnero P, Shih WJ, Gineyts E, Karpf DB, Delmas PD (1994) Comparison of new biochemical markers of bone turnover in late postmenopausal osteoporotic women in response to alendronate treatment. J Clin Endocrinol Metab 79: 1693-1700.

10. Kushida K, Takahashi M, Kawana K, Inoue T (1995) Comparison of markers for bone formation and resorption in premenopausal and postmenopausal subjects, and osteoporosis patients. J Clin Endocrinol Metab 80: 2447-2450.

11. Lotz J, Steeger D, Hafner G, Ehenthal W, Heine J, Prellwitz W (1995) Biochemical bone markers compared with bone density measurement by dual energy X-ray absorptiometry. Calcif Tissue Int 57: 253-257.

12. Hassager $C$, Jensen LT, Pødenphant J, Thomsen $K$, Christiansen C (1994) The carboxyl-terminal pyridinoline cross-linked telopeptide of type I collagen in serum as a marker of bone resorption: The effect of nandrolone decanoate and hormone replacement therapy. Calcif Tissue Int 54: 30-33.

13. Masters PW, Jones RG, Purves DA, Cooper EH, Cooney JM (1994) Commercial assays for serum osteocalcin give clinically discordant results. Clin Chem 40: 358-363.

14. Suzuki A, Ohara A, Yasui T, Mori K, Mori T (1984) Fundamental and clinical investigation of the estradiol direct radioimmunoassay kit. Clinical Endocrinol 33: 627-632 (In Japanese).

15. Johansen JS, Riis BJ, Delmas PD, Christiansen C (1988) Plasma BGP: An indicator of spontaneous 
bone loss and of the effect of oestrogen treatment in postmenopausal women. Eur J Cin Invest 18: 191195.

16. Slemenda C, Hui SL, Longscope C, Johnston CC (1987) Sex steroid and bone mass. A study of changes about the time of menopause. J Clin Invest 80: 1261-1269.

17. Yasumizu T, Kato J (1996) Concentrations of serum markers of type I collagen synthesis and degradation and serum osteocalcin in maternal and umbilical circulation. Endocr J 43: 191-195.

18. Riggs BL, Jowsey J, Goldschmith RS, Kelly PJ, Hoffman DL, Arnaud CD (1972) Short and long term effects of estrogen and synthetic anabolic hormone in postmenopausal osteoporosis. J Clin Invest 51: 1659-1662.

19. Smedsrød B, Melkko J, Risteli L, Risteri J (1990) Circulating C-terminal propeptide of type I procollagen is cleared mainly via the mannose receptor in liver endothelial cells. Biochem J 271: 345-350.

20. Gundberg CM, Hauschka PV, Lian JB, Gallop PM (1972) Osteocalcin: Isolation, characterization and detection. Methods Enzymol 107: 516-521.
21. Yasumizu T, Ogawa K, Kato J (1996) Comparison of clinicopathological characteristics in premenopausal and postmenopausal endometrial carcinomas: Analysis of endocrinologically evaluated cases. Jpn J Clin Oncol 26: 152-156.

22. Norimatsu K, Mori H, Uesato T, Yoshikawa T, Katsuyama N (1989) Bone mineral density of the spine and proximal femur in normal and osteoporotic subjects in Japan. Bone Mineral 5: 213222.

23. Mazess RB, Barden HS, Ettinger M, Johnson C, Dawson-Hughes B, Powell M (1987) Spine and femur density using dual photon absorptiometry in US white women. Bone Mineral 2: 213-219.

24. Uebelhart D, Schlemmer A, Johansen JS, Gineyts E, Christiansen C, Delmas PD (1991) Effect of menopause and hormone replacement therapy on the urinary excretion of pyridinium cross-links. $J$ Clin Endocrinol Metab 72: 367-373.

25. Garnero P, Gineyts E, Riou JP, Delmas PD (1994) Assessment of bone resorption with a new marker of collagen degradation in patients with metabolic bone disease. J Clin Endocrinol Metab 79: 780-785. 